\title{
O SERVIÇO DOS COLETORES DE LIXO: RISCOS OCUPACIONAIS VERSUS AGRAVOS À SAÚDE
}

\author{
Maria Lucia do Carmo Cruz Robazzi* \\ Elucar Gir* \\ Tokico Murakawa Moriya* \\ Janete Pessuto**
}

ROBAZZI, M. L. C. C. et al. O serviço dos coletores de lixo: riscos ocupacionais versus agravos

à saúde. Rev. Esc. Ent. USP, v.28, n.2, p. 177.90 , ago. 1994.

Os autores estudaram o tipo de serviço executado por 36 coletores de lixo, de uma cidade do interior do Estado de sāo Paulo, observando o elevado indice de ausências ao trabalho por problemas decorrentes de acidentes de trabalho e de saude, principalmente. Concomitantemente constaram värios riscos ocupacionais e o desuso de equi. pamentos de proteçāo individual a eles fornecidos, o que provavelmente contribui, entre outras causas, para o número de ausências ao trabalho.

UNITERMOS: Trabalhadores. Coletores de lixo. Acidentes de Trabalho.

\section{INTRODUÇÃO}

O lixo, um conjunto de resíduos sólidos, produtos das atividades humanas, deve ser desprezado o mais rapidamente possível do ambiente evitando assim que a sua permanência proporcione efeitos indesejáveis, aos individuos e à natureza. Nos locais onde esses resíduos predominam, inadequadamente depositados em ruas, calçadas, córregos, praças públicas ou em portas das casas, atraindo roedores, moscas ou outros insetos, há maior possibilidade de existir uma comunidade com doenças, tais como febre tifóide, cólera, diarréia, disenterias, antrax, conjuntivites, leptospirose, peste, triquinose, envenenamentos alimentares, meningites e outras ${ }^{29}$. Para que isso não aconteça, exige-se das administraçōes municipais um estudo cuidadoso e caracterizado sobre cada tipo de lixo produzido, bem como sobre equipes adequadas de coleta, para recolhê-los e dar-lhes um destino apropriado ${ }^{25}$.

Em geral, sob a responsabilidade de departamentos de limpeza pública, o trabalho de recolhimento dos lixos tende a se tornar crescentemente mais

\footnotetext{
- Professoras. Escola de Enfermagem de Ribeiráo Preto, USP, Departamento de Enfermagem Geral e Especializada.

A primeira autora é Enfermeira do Trabalho.

- Mestranda. Escola de Enfermagem de Ribeirão Preto, USP, Enfermeira do Trabalho.
} 
complexo, a medida em que aumentam as populações, principalmente urbanas. $O$ contacto frequente com agentes nocivos à saúde o caracteriza como um dos mais arriscados e insalubres, podendo a observação de riscos ocupacionais aos trabalhadores ser feita, até mesmo por leigos. Executado rotineiramente por coletores de lixo ou lixeiros, verifica-se que essas pessoas săo predominantemente do sexo masculino, possuem baixo nivel escolar e precisam da atenção e da colaboração da comunidade, para o poderem realizar sem problemas.

Alguns autores estudaram os perigos de se manipular o lixo e os agravos à saúde que podem ocorrer aos coletores, destacando, desde comprometimentos respiratórios ${ }^{4,7,9,19,22.29}$, afecçōes musculares ${ }^{9,14,19,22.31}$, patologias de coluna $^{11,12,18,20,23,32}$, afecções cardiovasculares ${ }^{26.31}$, perdas auditivas ${ }^{13}$, tabagismo e alcoolismo ${ }^{1.23 .28}$, até acidentes de trabalho durante a realização da cole$\mathrm{ta}^{8,10,11.27,28}$. Esses acidentes parecem estar associados a vários fatores, tais como acondicionamento inadequado do lixo por parte da população ${ }^{16}$, manobra com veículos ${ }^{11}$, mordedura de animais ${ }^{1.9}$, cortes, contusões e outras lesões semelhantes ${ }^{1,10,11,23.27,30}$, atropelamentos ${ }^{11}$, além do desuso ou o uso inadequado, por parte dos coletores dos EPIs, ou seja, dos equipamentos de proteção individual ${ }^{11.28}$

No Brasil esses trabalhadores costumam receber uma remuneração que parece variar entre 1 (um) a 3(três) salários mínimos vigentes ${ }^{11.27 .28}$. Apesar de em tal montante ser acrescido uma determinada quantia relacionada à insalubridade do serviço, dificilmente o salário total condizente com a importância do serviço executado por eles. Sendo um dos protissionais mais qualificados para essa importante tarefa.

Constituindo então um grupo de trabalhadores que realizam atividades laborais de riscos, que podem provocar danos para a saúde, necessitam contar, em suas empresas, com a constante atenção de pessoas qualificadas. profissionais da área de saude do trabalhador, que lhes possam proporcionar atendimentos específicos de saúde e programas educativos, atenuando assim as consequências geradas pelos riscos. $O$ enfermeiro, com o conhecimento teórico-prático adquirido em seus cursos de graduação e de especialização em Enfermagem do Trabalho, terá capacidade para executar nas empresas numerosas atividades relacionadas à promoção da saúde dos mesmos.

Compreendendo dessa forma que existem riscos laborais que podem afetar a saúde dos coletores de lixo no cotidiano de seu trabalho, realizou-se o presente estudo, em uma cidade do interior do Estado de São Paulo, que teve como objetivos gerais investigar:

1 - o número de afastamentos de trabalho ocorridos por problemas de saúde;

2 - o uso de equipamentos de proteção individual (EPIs) durante a execução do trabalho;

3 - os principais problemas que acontecem aos coletores de lixo durante a execução do seu trabalho.

Acredita-se que a análise dos resultados obtidos pode fornecer subsídios para se conceber um panorama da situação laboral e de saúde desses traba- 
lhadores e a partir daí, traçar condutas, buscando maneiras de resolver os problemas com os quais certamente eles convivem.

\section{METODOLOGLA}

A amostra desse estudo foi constituida por 36 coletores de lixo $(67,92 \%)$, de uma população de 53 trabalhadores, servidores de uma empresa pública, com superintendência e administração próprias, pertencente a Prefeitura Municipal de uma cidade interiorana do Estado de São Paulo, com aproximadamente 450.000 habitantes.

Para a seleção dessa amostra, considerou-se os seguintes critérios: aincluir apenas os homens que trabalhasses em caminhōes de coleta de lixo, excluindo-se os motoristas, os que fazem o serviço de varreção de praças, calçadas e feiras-livres ou os que trabalham em outros serviços e eventualmente realizam substituiçōes de trabalhadores faltosos; b- incluir os que estivesses lúcidos, năo-alcoolizados e aptos a serem submetidos a uma entrevista; c- incluir os que concordassem em ser entrevistados e estivessem presentes na semana determinada para se realizar a coleta de dados.

Dessa forma. o estudo se realizou em três etapas: a- primeiramente entrevistou-se os 36 trabalhadores, após autorização da Prefeitura Municipal da cidade, de acordo com os critérios descritos anteriormente; b- em etapa posterior, buscou-se na empresa informaçōes contidas nos prontuários dos 36 entrevistados e c- como última fase, realizou-se a observaçào da maneira como era executado o trabalho, buscando verificar se eles utilizavam os EPIs, durante a execução do mesmo.

Os seguintes instrumentos foram utilizados: para a realização das entrevistas, elaborou-se um formulário (Anexo I), contendo perguntas relacionadas ao uso de equipamentos de proteção individual (EPIs); para a sistematização da observação dos coletores de lixo durante o trabalho, elaborou-se uma ficha de observação, relacionada ao uso dos EPIs (Anexo 2). Deixou-se tambèm espaço nessa ficha para anotaçōes descritivas dos observadores, que lhes permitissem realizar consideraçōes referentes ao trabalho executado e descrever os principais problemas acontecidos durante a execução do mesmo.

Optou-se por realizar as entrevistas na sede da empresa, por ser o local centralizador dos trabalhadores, ou seja, o lugar de onde eles saem para iniciar a sua jornada de trabalho e retornam apos a mesma. As entrevistas foram todas realizadas por uma das autoras deste estudo durante o periodo de l(uma) semana após os vários turnos de trabalho; a observação dos coletores de lixo, quanto ao uso dos EPIs e no que se refere à existência de problemas, durante a execução do trabalho, foi feita, também durante o periodo de l(uma) semana pelas demais pesquisadoras, seguindo-à certa distância os veículos coletores, em setores diversificados da cidade e o grupo de trabalhadores, em turnos diurnos e noturnos variados, conseguindo-se observar dessa maneira 6(seis) caminhões coletores de lixo e 24 trabalhadores. 


\section{RESULTADOS E DISCUSSĀO}

Através dos dados obtidos nos prontuários da empresa. constatou-se que os empregados da limpeza pública são contratados em regime de Consolidação das Leis do Trabalho (CLT), recebem 1(um) salário mínimo por mês, acrescido de taxas referentes à assiduidade e insalubridade e possuem numerosas licenças e/ou afastamentos, acontecidos durante a execução do trabalho. Tais ausências, em sua grande maioria, foram determinadas por médicos do Serviço de Assistência Social da cidade, instituição essa que presta atendimento aos trabalhadores da Prefeitura Municipal e suas empresas ou departamentos conveniados, já que nesses estabelecimentos, não existe profissional médico ou de enfermagem especialista na área de saúde do trabalhador.

A maior parte dessas ausências foi concedida diante das ocorrências. de acidentes de trabalho; outros afastamentos aconteceram devido a doenças que o trabaihador apresentou, tais como gripes, estados de mal-estar, dores de cabeça e situaçōes que requereram ou não internação hospitalar. Outras ainda tiveram como causas, mortes de pessoas da família, faltas injustificadas, nascimentos de filhos e situaçỏes assemelhadas.

As ausências ao trabalho, correlacionadas com o tempo em que os lixeiros trabalharam desde a sua contratação na empresa, encontram-se demonstradas na tabela da pág seguinte.

A tabela 1 mostra que os 36 coletores de lixo pertencentes a amostra deste estudo precisaram se ausentar 166 vezes ao trabalho. Desconhece-se o número de dias perdidos de serviços resultantes desses afastamentos. Considerando-se, no entanto, nesse estudo, que a maior parte dos afastamentos ocorreu por acidentes do trabalho e hipotetizando que em decorrência dos mesmos os lixeiros ficaram afastados uma média de 14 dias (a partir do $15^{\circ}$ dia, sabe-se que é o Seguro Social que lhes paga os benefícios devidos e nāo mais a empresa contratante), imagina-se que tenha sido muito elevado o número destes dias perdidos de trabalho. Parece, entretanto, nāo existir, correlação entre o número dessas ausências e o tempo de serviço dos trabalhadores na empresa. Exemplifica-se com o que se segue: em relação aos 18 empregados que trabalhavam na empresa há 50 meses, verificou-se que 1 (um) deles, por exemplo, apresentou um considerável número de afastamentos (17) nesse periodo; por outro lado, outros 2 (dois) trabalhadores, também pertencentes a esse grupo de 18 pessoas, tiveram, respectivamente, 0 (zero) e $1(\mathrm{um})$ afastamento. $O$ trabalhador que estava contratado há 60 meses precisou se afastar apenas uma única vez ao serviço; em contrapartida o que possuía menos tempo no emprego ( 13 meses) ausentou-se 8 vezes.

Dessa forma torna-se difícil inferir, para essa amostra, que quanto maior é o tempo de emprego, maior é o número de afastamentos ou realizar algum outro tipo de inferência. 
TABELA 1. Distribuição de 36 coletores de lixo, empregados de uma emprean pública, em uma cidade do interior paulista, seguado o número de vezes em que se ausentaram do trabalho, a partir do tempo de serviço na empresa.

\begin{tabular}{|c|c|c|}
\hline numero de trabalhadores & $\begin{array}{l}\text { tempo de serviço na empresa } \\
\text { (em meses) }\end{array}$ & $\begin{array}{c}\text { numero de ausèncias ao } \\
\text { trabalho (em dias) }\end{array}$ \\
\hline 1 & 13 & 8 \\
\hline 1 & 16 & 1 \\
\hline 1 & 19 & 2 \\
\hline 1 & 20 & 1 \\
\hline 1 & 22 & 5 \\
\hline 1 & 23 & 6 \\
\hline 1 & 24 & 11 \\
\hline 2 & 30 & 5 \\
\hline 1 & 35 & 2 \\
\hline 1 & 39 & 8 \\
\hline 1 & 43 & 1 \\
\hline 1 & 44 & $\ddot{0}$ \\
\hline 1 & 46 & 6 \\
\hline 1 & 47 & 3 \\
\hline 1 & 48 & 2 \\
\hline 18 & 50 & 93 \\
\hline 1 & 56 & 7 \\
\hline 1 & 60 & 1 \\
\hline Total 36 & & 168 \\
\hline
\end{tabular}

Apesar de não se ter as informaçōes do número de empregados admitidos e demitidos na empresa, nesse periodo de 60 meses, para se estimar os Coeficientes de Frequência e de Gravidade para Acidentes de Trabalho, com esse tipo de trabalhador, tal como foi realizado na cidade de São Paulo (SP) ${ }^{29}$, acredita-se que um total de 166 ausências ao trabalho, calculadas para 36 trabalhadores é elevado, pois estimando-se a média aritmética, obtém-se 4,61 afastamentos, por pessoa, nessa ocupação.

Os estudos efetuados por FARIA; ILÁRIO ${ }^{11}$, MARQUES et al. ${ }^{16}, \mathrm{PE}$. REIRA $^{23}$, SILVA $^{8}$, SILVA $^{29}$, entre outros, também indicam que o número de afastamentos dos lixeiros ao trabalho é elevado, por motivos os mais 
variados, mas principalmente em decorrência de acidentes laborais, informações essas coincidentes com os resultados obtidos nesse estudo.

MARQUES et al. ${ }^{16}$, por exemplo, comentam que o Serviço Público de Manutenção Urbana da cidade de Santo André, (SP), detinha o maior índice de acidentes, comparado aos demais serviços; ILÁRIO ${ }^{11}$ na cidade de Campinas (SP), relata que encontrou nesses trabalhadores a incidência de 137 acidentes em 1985 e 152 em 1986, números esses calculados por 100 coletores/ano. FARIA; SILVA ${ }^{8}$ colocam que na cidade de Belo Horizonte (MG), do total de 4095 acidentes, os garis, lixeiros e capinadores sofreram 87, ou seja, $2,12 \%$ do total; SILVA ${ }^{29}$ explica que na cidade de São Paulo (SP), os Coeficientes de Frequência de Gravidade de acidentes de trabalho entre coletores de lixo são maiores que entre outros trabalhadores de ramos diversos, tais como os empregados de metalurgias, indústrias químicas e outras. PEREI$\mathrm{RA}^{23}$ encontra no Rio de Janeiro ( $\left.\mathrm{RJ}\right), 1792$ acidentes na Companhia Municipal de Limpeza Urbana daquela cidade, acontecidos durante 1 (um) ano de trabalho, a grande maioria entre os coletores de lixo.

Supōe-se então, que essa ocupaçāo, tal como é realizada, pode influenciar diretamente nos números de ausências elevados, principalmente naquelas resultantes de acidentes de trabalho.

Segundo ILÁRIO ${ }^{11}$, não se justifica a situaçāo deficitária encontrada entre esses trabalhadores; nāo há necessidade de grandes investimentos financeiros para a proteçāo da saúde dos mesmos e medidas simples poderiam trazer benefícios, como por exemplo, a instituição de exames médicos admissionais, educação em saude, principalmente na área de prevençāo de alcoolismo, imunizaçòes básicas e outras.

Por outro lado, é consenso geral que quando se aborda a questāo das ausências por acidentes de trabalho no Brasil, a situaçāo é muito mais sèria do que pode aparentar. Autores como COHN et $\mathrm{al}^{6}$ concluem que essa questāo é dramática; o indivíduo diminui ou finda a sua capacidade individual de trabalho e isso também significa que lhe cessa o direito de viver dignamente. ou até mesmo o direito à própria vida. A partir dessa compreensão de $\mathrm{COHN}$ et $\mathrm{al}^{6}$, entende-se que $\mathrm{o}$ acidente de trabalho pode ser considerado um problema de saúde pois através dele, a mesma se desgasta. E é sem alterações e desgastes na saúde, com as pessoas aptas a trabalharem sem prejuízo de sua integridade, que se vive com dignidade e pode-se considerar que um individuo é saudável.

Apesar da indenização que o trabalhador acidentado tem direito a receber, variando evidentemente, quanto à gravidade do acidente. CAMPOS ${ }^{3}$ comenta que a mesma não empobrece e nem enriquece, mas o responsável pelo acidente é obrigado a repor os benefícios da vítima na situação em que estariam. sem o dano. Acredita-se, entretanto, que o trabalhador acidentado só tem a empobrecer, mesmo recebendo a mencionada indenização, compreendendo-se o empobrecimento no próprio constrangimento com o qual, muito provavelmente deve permanecer uma pessoa sem alguma parte de seu corpo, em relação ao meio social onde vive, ou com algum outro tipo de lesão, não necessariamente tão traumática, mas que lhe diminua a capacidade para o trabalho. 
Tecendo comentários a respeito das condições de trabalho e da situação de saúde dos operários brasileiros, MEDRADO-FARIA ${ }^{17}$ coloca que esses aspectos relacionam-se, por um lado, com o quadro geral de saúde da população brasileira e pelo outro, com os problemas específicos das diferentes formas de desgastes da saúde, dependentes da divisão técnico-social do trabalho, como os acidentes de trabalho, intoxicaçōes, doenças relacionadas com a organização do trabalho e outras. As questōes referentes à saúde do trabalhador no país, apesar do intenso desenvolvimento industrial dos últimos 38 anos, ainda são pouco consideradas e somente agora começam a ser melhor pesquisadas e discutidas.

Quanto ao aspecto numérico, que pode indicar a situaçāo real dessa infortunistica, a maior parte dos estudiosos esclarece que acontece no país uma situação grave, que é a subnotificação desses acidentes. Como explica MACEDO $^{15}$, os índices de acidentes de trabalho e doenças profissionais deerescem sempre no Brasil, pois muitos médicos acham dispensáveis a emissāo das Comunicaçōes de Acidentes de Trabalho (C.A.T.).

MEDRADO-FARIA ${ }^{17}$ afirma que o conhecimento da existência de subregistros e de sonegaçāo de informações sobre essas doenças e acidentes, no país, é consenso geral. As informaçōes são precárias, pouco fidedignas e incompletas, principalmente no que diz respeito às questōes relacionadas ao trabalho.

Acredita-se entāo que nesse estudo, o número de ausências dos coletores de lixo ao trabalho, observados nos registros da propria empresa, provavelmente é menor que o numero real de afastamentos acontecidos, considerando-se as informações do empregador, que a grande maioria desses afastamentos aconteceu em decorrência de acidentes de trabalho. Estes muitas vezes não são notificados, porque os próprios trabalhadores não acreditam serem importantes e porque as empresas não costumam notificar os considerados de pequeno porte. BISOTTO et al. ${ }^{1}$ mostram que em Campinas, por exemplo, ferimentos de pequeno porte, intoxicações por inseticidas, pneumonias, cãimbras, lombalgias e outros problemas semelhantes, acontecidos entre os coletores de lixo, não costumam ser computados, por serem entendidos como tendo pouca significância.

Quanto ao uso de equipamentos de proteção individual (EPIs), as respostas dos entrevistados, bem como a observação realizada pelas pesquisadoras encontram-se demonstradas na Tabela 2 na página seguinte.

Durante o preenchimento da Ficha de Observação (Anexo 2), verificouse que a maneira como se procede o serviço de recolhimento de lixo, da cidade do estudo em questão, torna-se proporcionadora de riscos à saúde dos coletores.

Animais soltos nas ruas, pisos derrapantes, caminhōes recolhedores de lixo sem luzes de sinalizaçāo traseira, ausência de equipamentos protetores, o ritmo acelerado em que é realizado o trabalho, brincadeiras durante o mesmo, embriaguez, foram alguns dos problemas observados pelas autoras deste estudo, que podem levar os trabalhadores a se submeterem a riscos à sua integridade corporal. A população não costuma acondicionar corretamen- 
te o lixo, colocando objetos cortantes e/ou perfurantes nos sacos de polietileno a serem recolhidos, sem avisarem os lixeiros desse fato; esses, por sua vez, principalmente os que realizam o trabalho no período diurno, percorrem zonas densamente povoadas, entrando em contacto direto com o trânsito das ruas, correndo sérios riscos de sofrerem atropelamentos, submetendo-se a variados níveis de poluição sonora e, além disso, contaminando-se pela exposição direta aos resíduos coletados.

TABELA 2. Distribuiçāo de coletorea de lizo, empregados de uma empresa pública em uma cidade do interior paulista segundo as suas informaçōes e a observação das pesquisadoras, quanto ao uso de equipamentos de proteçāo individual (EPIs), durante a jornada de trabalbo.

Informação dos trabalhadores

\begin{tabular}{|c|c|c|c|c|c|c|c|c|c|c|c|c|}
\hline \multirow{2}{*}{ EPIs } & \multicolumn{2}{|c|}{ Usa } & \multicolumn{2}{|c|}{ Nảo usa } & \multicolumn{2}{|c|}{ Total } & \multicolumn{2}{|c|}{ Usa } & \multicolumn{2}{|c|}{ Não usa } & \multicolumn{2}{|c|}{ Total } \\
\hline & $\mathrm{N}$ & $\%$ & $N$ & $\%$ & $\mathrm{~N}$ & $\%$ & $\mathrm{~N}$ & $\%$ & $\mathrm{~N}$ & $\%$ & $\mathrm{~N}$ & $\pi$ \\
\hline $\begin{array}{l}\text { Calça e } \\
\text { jaleco }\end{array}$ & 36 & 100,0 & - & - & 36 & 100,0 & 23 & 92,8 & 1 & 4,2 & 24 & 100,0 \\
\hline Luvas & 20 & 55,5 & 16 & 44.4 & 36 & 100,0 & 2 & 8,3 & 22 & 91,6 & 24 & 100,0 \\
\hline Calçados & 36 & 100.0 & - & - & 36 & 100,0 & 24 & 100.0 & - & - & 24 & 100.0 \\
\hline $\begin{array}{l}\text { Chapéu ou } \\
\text { boné }\end{array}$ & 17 & 47,2 & 19 & 52.8 & 36 & 100,0 & 10 & 41.7 & 14 & 58,3 & 24 & 100,0 \\
\hline
\end{tabular}

Alguns dos problemas observados nesse estudo, foram descritos por vários autores: ILÁRIO ${ }^{11}$, por exemplo, ao descrever esta ocupaçāo na cidade de Campinas - SP, utilizou-se da expressão "desabalada carreira" para caracterizar a velocidade utilizada pelos coletores de lixo, durante a realização de seu trabalho; SILVA; CARVALHO ${ }^{30}$, observaram a grande probabilidade de ocorrerem acidentes por atropelamentos, levando-os à mutilaçōes e mesmo à morte. PEREIRA ${ }^{23}$ e ILÁRIO ${ }^{11}$ comentaram sobre o estado de embriaguez em que trabalham muitos desses homens, sendo que PEREIRA ${ }^{23}$ mencionou que o efeito do álcool é um dos que estão ligados as incidências dos eventos acidentários que encontrou entre esses trabalhadores. ILÁRIO ${ }^{11}$, diante da elevada taxa de alcoolismo descoberta entre os coletores de lixo, significativamente maior que as mencionadas em pesquisas latinoamericanas, propōe que o mesmo seja considerado Doença do Trabalho para essa categoria ocupacional.

Diante dessas informaçōes e das observaçōes registradas na ficha de observação (anexo 2), que puderam ser feitas neste estudo, acredita-se que o trabalho dos coletores de lixo, da forma como é realizado, leva-os a sofrerem numerosos acidentes laborais e conseqüentemente, afastamentos ao serviço, o que explica os dados apresentados na Tabela 1.

Pode-se observar na tabela 2 que todos (100\%) os sujeitos deste estudo informaram, quando entrevistados, que usavam calças compridas, jalecos e calçados de solado de borracha do tipo "tênis" ou "alpargatas"; $20(55,5 \%)$ referiram-se usar luvas e $17(47,2 \%)$ informaram o uso de chapéus ou bonés, 
adquiridos por eles mesmos, encontrados no lixo recolhido ou no aterro sanitário da cidade. Entretanto, dos 24 trabalhadores que foram observados, o número dos que não utilizam esses equipamentos é maior, discordando das respostas obtidas durante as entrevistas. Aqueles que informaram nāo usar luvas, alegaram motivos variados, tais como o fato delas terem se estragado e não terem sido repostas pela empresa; atrapalharem quando os trabalhadores seguram os sacos de lixo ou os recipientes de metal; manterem as mão com forte e nauseante odor, entre outros comentários.

Segundo CAMPANHOLE; CAMPANHOLE ${ }^{2}$, “a empresa é obrigada a fornecer aos empregados, gratuitamente, equipamentos de proteção individual adequado ao risco e em perfeito estado de conservação e funcionamento, sempre que as medidas de ordem geral não ofereçam completa proteção contra os riscos de acidentes e danos à saúde dos empregados".

Esse fato parece não estar acontecendo com os trabalhadores desse estudo, conforme se apurou durante as entrevistas. Acredita-se então que a empresa responsável pela limpeza urbana da cidade, colabora com a possibilidade dos empregados sofrerem grande risco de se acidentarem, ao realizarem o seu ofício, por não repor aos mesmos os equipamentos estragados.

Observa-se também que outras empresas da cidade, principalmente as municipais, não se preocupam em realizar uma efetiva fiscalização dos empregados, durante a realização do seu trabalho, nem mantém programas educativos que expliquem aos mesmos a importância de utilizarem equipamentos, para a sua própria segurança. A grande maioria delas mesmo sendo de caráter particular, não possuem serviços de saude ocupacional; são raras as que têm, entre o seu quadro de empregados, enfermeiros do trabalho e pessoal técnico em segurança.

Quando os coletores de lixo investigados nesse estudo, usam calças compridas e jalecos de cor azul-escuro, com identificação da empresa em letras brancas. SILVA; CARVALHO ${ }^{30}$ demonstraram que o índice de acidentes ocorridos com esses trabalhadores, na Guanabara, diminuiu, após terem sido realizadas algumas modificações na cor dos uniformes (de azulão para abóbora), nos calçados e na obrigatoriedade no uso de luvas. Entende-se, portanto, que o uso de roupas de cores escuras pode ser um dos fatores que predisponha à acidentes laborais, principalmente se o trabalho for realizado a "céu aberto", como é o caso dos coletores de lixo e se as mesmas forem utilizadas durante o periodo noturno, situação essa encontrada nesse estudo.

Para quem trabalha nesse tipo de serviço, segundo PHILLIP $\mathrm{Jr}_{.}{ }^{24}$ e a ORGANIZAÇÃO PANAMERICANA DA SAÚDE ${ }^{21}$, o uso de EPIs deve ser obrigatório, sendo basicamente os uniformes compostos por: roupa, capacete, boné, luvas, capa, calçados, colete reflexivo e plaqueta de identificação. Acrescenta OLIVEIRA ${ }^{19}$ que os que trabalham a noite deveriam usar vestuarios com faixas de pintura especial que possa refletir a luz dos veiculos.

No que se refere à capa, os trabalhadores mencionaram que é de material plástico, para proteção contra chuva; por ser incômoda e pesada, dificulta-lhes os movimentos e muitos preferiam não utilizá-la. As que se estragavam também não eram repostas pela empresa. 
Por exercer esse tipo de ocupaçāo, os trabalhadores deveriam também ser melhores protegidos nos membros inferiores, no caso, através de calçados antiderrapantes e protetores contra riscos de origem mecânica e agentes biológicos, tal como recomendado por COELHO FILHO; LOBATO ${ }^{5}$.

Provavelmente o número elevado de afastamentos ao trabalho, demonstrado na Tabela 1, está correlacionando aos dados da Tabela 2, pois us coletores de lixo desse estudo, somando-se ao fato de que os equipamentos não sāo repostos, não costumam utilizá-los, apesar da insalubridade do trabalho que executam.

\section{CONCLUSÕES E RECOMENDAÇŌES}

Diante dos resultados obtidos nessa investigação, conclui-se que:

- o número de ausências ao trabalho por problemas decorrentes durante a realização do mesmo é elevada, estimando-se a média de 4,61 ausências para 60 meses de trabalho, por pessoa, conforme os dados obtidos na empresa municipal, contratante dos coletores de lixo;

- apesar de não se ter especificamente os números corretos, a grande maioria dessas ausèncias ocorreram por acidentes de trabalho, além de outros problemas de saúde de forma geral;

- mesmo afirmando o contrário, esses trabalhadores não têm o hábito de utilizarem EPIs durante a realização de seu oficio. Os equipamentos, por sua vez, quando estragados, gastos ou perdidos, não costumam ser repostos pela empresa;

- a cor dos uniformes é escura, inadequada para o trabalho realizado, principalmente durante a noite, os sapatos do tipo "tênis" ou "alpargatas", que possuem solado de borracha e são antiderrapantes costumam ser usados quando os lixeiros os compram, quando os encontram nos sacos de lixo ou no aterro sanitário da cidade, porque nāo são fornecidos pela empresa;

- os coletores de lixo trabalham em ritmo acelerado, correndo o risco de caírem ao solo e sofrerem acidentes severos, principalmente quando realizam turnos diurnos, sobre condiçōes de tráfego mais intenso, tendo probabilidade de colidirem com os veículos em trânsito;

- a população da cidade colaboram para que eles se acidentem, uma vez que acondiciona inadequadamente o lixo, colocando objetos cortantes, perfurantes ou com excesso de peso, no interior dos sacos plásticos;

- há entre os trabalhadores os que realizam o serviço em estado de embriaguez, além de outros que fazem brincadeiras, tornando-se desatentos durante o trabalho, aumentando assim a possibilidade de se acidentarem. A empresa, por outro lado, não realiza um efetivo esquema de fiscalizaçāo, permitindo que esses problemas aconteçam, prejudicando os seus próprios empregados.

Diante dessas conclusões, recomenda-se que a maior atenção seja dada ao ofício executado por esses individuos. Algumas medidas poderiam ser acionadas, por parte das autoridades responsáveis pela Saúde Ocupacional 
na cidade e também por parte da empresa que contrata esses trabalhadores. Campanhas educativas, por exemplo, tornam-se fundamentais nessa situação, dirigidas tanto à população geral, esclarecendo-as sobre as maneiras corretas do acondicionamento do lixo, quanto aos próprios trabalhadores, treinando-os adequadamente para o serviço, conscientizando-os sobre a necessidade de utilização de equipamentos para se protegerem, durante a execuçảo do mesmo. Maior atençāo deveria ser dada por parte do empregador, valorizando os empregados através de pisos salariais condizentes com a importância do trabalho que executam, fornecendo-lhes equipamentos de proteção adequados e treinando-os para usá-los, visando a diminuição dos elevados números de ausências encontradas.

Uma efetiva fiscalização da empresa, feita através dos órgãos oficiais existentes e adequados para isso, deveria acontecer, objetivando, sobremaneira, a diminuição dos riscos laborais no trabalho dos lixeiros.

Acredita-se que a contratação.de um enfermeiro, diretamente no setor de limpeza ao qual eles estão vinculados, pode também ser uma das maneiras que vá contribuir para a diminuição do número de ausências ao serviço. Com especialização na área de Enfermagem do Trabalho, este profissional, através de seu conhecimento acadêmico, pode orientar os coletores sobre os riscos à saúde, aos quais são submetidos, realizando medidas tanto preventivas quanto terapêuticas, dentro de suas atribuições e competências legais.

\section{CONSIDERAÇÕES FINAIS}

Após a apresentação dos resultados à empresa contratante dos coletores de lixo, algumas dessas recomendaçōes foram colocadas em prática. Reuniōes realizadas e projetos de trabalhos feitos, a pedido de membros da equipe técnica, que eram funcionários os quais ocupavam cargos relevantes no setor da limpeza urbana, resultaram em modificações concretas, tais como alteraçăo na cor dos uniformes, de azul-escuro para tonalidade mais clara, próxima do amarelo, obrigatoriedade aos coletores de lixo de registrarem seu horário de saida, após trabalharem 8 (oito) horas por dia, diminuindo assim o ritmo veloz que imprimiam na execução do serviço entre outras.

A conquista mais importante, no entanto, segundo a opinião das autoras deste estudo, foi a contratação, por parte da empresa de uma enfermeira, com especializaçāo em Enfermagem do Trabalho, objetivando um segmento mais próximo das condiçōes de saúde e de trabalho dos coletores de lixo e demais empregados do local.

Pretende-se, futuramente, dando sequeencia ao presente estudo, realizar outro, para avaliar se efetivamente acontecerá a desejada melhoria da situação dos trabalhadores-da coleta de lixo, dessa cidade.

ROBAZZI, M. L . C. C. et al. The garbage collectors work: occupational risks versus health damages. Rev. Esc. Enf. USP, v.28, n.2, p. 177-190, 1994. 
The authors studied the kind of work a sample of 36 garbage collectors have been doing in a city of the State of Säo Paulo. A high frequency of occupational accidents and sick-due to health problem and some occupational risks was observed among them, and also that these worker haven't worn the individual protection equipament received, that probably contributes to such number of stop workwing.

UNITERMS: Workers. Garbage collectors. Work Accidents

\section{REFERÊNCIAS BIBLIOGRÁFICAS}

1. BISOTTO, D. et al. Acidentes do trabalho no coletor de lixo. Campinas, Fac.Ciências Mèdicas, UNICAMP, 1979./mimeografado/

2: CAMPANHOLE, A.; CAMPANHOLE, H.L. Consolidação das leis do trabalho. 58.ed. São Paulo. Atlas, 1982.

3. CAMPOS, J.L.D. Responsabilidade civil e criminal decorrente do acidente do traba tho na Constituiçào de 1988 - Ação Civil Pública - Minstério Público e o Ambiente do Trabaiho. Rev.Trib ., v.52, n.12, p.423-36, 1981.

4. CHAUMONT, A.J. et al. La collete des ordures et dechets, ses risques professionels. Arch.Mal.Profession , v. 36, a.7/8, p.429-34, 1975.

5. COELHO FILHO. O.O.; LOBATO, F.J.C. Segurança e higiene do trabalho na limpeza publica de Belém. In: CONGRESSO NACIONAL DE PREVENÇÁO DE ACIDENTE DO TRABALHO. 14, Rio de Janeiro. 1975. Anais. São Paulo, Arte e Texto, 1975. p.689-703.

6. COHN. A. et al. Acidente do trabalho: uma forma de violência. Sāo Paulo, Brasiliense. 1985 .

7. DUCEL, G. et ai. Importance de l'exposition bactérienne chez les employés de la voirie charges de la leve e des ordures. Soz. Praventivmed, v.21. n.4. p.136-8. 1976.

8. FARIA, M.P.; SILVA, A.M. Analise de acidentes do trabalho ocorridos durante parte do ano de 1983 na Grande Belo Horizonte(MG). Rev.Bras.Saúde Ocup., v.53, n.14, p.26-32, 1986.

9. FORATTINI. O. Aspectos epidemológicos ligados ao lixo. In: UNIVERSIDADE DE SÄO PAULO. Faculdade de Higiene e Saúde Pública. Lixo e limpeza pública. São Paulo, USP/OMS/OPS, 1969. cap.3. p.1-19.

10.GRIECO, A. et al. Le condizioni de lavoro e di salute di un gruppo omogeneo dinetturbini: analisi e indicazioni preventive. Med.Lavoro, v.66, n.5, p.405-48, 1975.

11.ILARIO, E. Estudo da morbidade em coletores de lixo em um grande centro urbano. Rev.Bras.Saúde Ocup., v.66. n.17, p.7-13. 1989.

12.KENPER. H.C.G. et al. The physical and physiological workload of refuse collectors. Ergonomics, v.33, n.12, p.1471-86, 1990 .

13. KESSLER, M. et al. Área de ruidos em serviço público de limpeza doméstica. The Arbeitsmed, v.17, p.34-9, 1987.

14. LASCOE, R. Basuras, evacuacion. In: OFICINA INTERNACIONAL DEL TRABAJO. Enci clopedia de medicina, higiene y seguridad del trabajo. Madrid, INP, 1974. v.1. p.235-6.

15.MACEDO, O. O mito insalubre. Humanidades , v.6, n.22, p.72-5, 1989.

16. MARQUES. E. et al. Acidentes nos serviços de limpeza pública. In: CONGRESSO NACIONAL DE PREVENCĀO DE ACIDENTES NO TRABALHO, 19, Brasilia, 1980. Anais. São Paulo. FUNDACENTRO, 1981, p.314-9. 
17.MEDRADO-FARIA, M. A. Saúde e trabalho industrial: condiçōes de saúde dos operários brasileiros. Ci.Cult, v.40, n.10, p.967-75, 1988.

18.MENONI, O, et al. Movimentazione di pesi e patologie del rachide in portasacchi addetti alla raccolta della nettezza urbana. In: SEMINARIO NAZIONALE LAVORE E PATOLOGIA DEL RACHIDE, Atti, Milano, 1989. p.313-19.

19.OLIVEIRA, W.E. Saneamento do lixo. In: UNIVERSIDADE DE SĀO PAULO. Faculdade de Higiene e Saúde Pública. Lizo e limpeza pública. São Paulo. USP/OMS/OPS, 1969. cap.1, p.1.18, 1969.

20.ONISHI, N.; NOMURA, H. Low back pain in relation to physical work capacity and local tenderness. J.Hum.Ergol ., v.2, p.119-32, 1973.

21.ORGANIZAÇÃO PANAMERICANA DA SAÚDE. La eliminacion de basuras y el control de insectos y roedores. Washington, 1963. (Publicaçāo Científica, 75).

22.PACHECO, J.N. Consideraçóes sobre os processos de disposição final do lixo; aspectos gerais que interessam à saude pública. Arq.Hig.Saúde Publ., v.26, n.89, p.199-216, 1961.

23.PEREIRA, A.S.O. Acidente de trabalho em limpeza urbana Rio de Janeiro, COMLURB, 1978. v.1.

24.PHILIPP Jr., A. Sistems de residuos sólidos: coleta e transporte do meio urbano. São Paulo, 1979. 185p. Dissertação(Mestrado) -Faculdade de Saude Pública, Universidade de São Paulo.

25.PINTO, M.S. A coleta e disposiçăo do lixo no Brasil. Rio de Janeiro, Fundaçào Getúlio Vargas, 1979.

26. REINHART. V. The dangerous world of a sanitation worker. Job.Safety Health, v.4, a.1. p.22-6, 1976.

27.ROBAZZI, M.L.C.C. Contribuiçāo ao estudo sobre coletores de lixo: acidentes de trabalho ocorridos em Ribeirão Preto, Estado de São Paulo, no periodo de 1986 a 1988. Rjbeirão Preto, 1991. 185p. Tese (Doutorado)-Escola de Enfermagem de Ribeirào Preto. Universidade de São Paulo.

28. Estudo das condiçōes de vida, trabalho e riscos ocupacionais a que estảo sujeitos 08 coletores de lixo da cidade de Ribeirāo Preto, Estado de São Paulo. Ribeirảo Preto, 1984. 120p. Dissertação (Mestrado) -Escola de Enfermagem de Ribeirāo Preto, Universidade de São Paulo.

29.SILVA, E.P. Condiçōes de saúde ocupacional dos lixeiros de Sāo Paulo. São Paulo 1973. 89p. Dissertaçāo (Mestrado). Faculdade de Saúde Pública. Universidade de Sào Paulo.

30.SILVA. L.M.B.; CARVALHO. A.S. Acidentes em limpeza urbana na Guanabara. In: CON. GRESSO NACIONAL DE PREVENÇÄO DE ACIDENTE DO TRABALHO, 13, São Paulo, 1974. Anais. Sảo Paulo, DNSHT, 1974, p.761-71.

31.SLIEPCEVICH, E.M. Effect of work conditions upon the health of the uniformed sanitationmen of New York city. Springfield. Faculty of Springfield College, 1955. Dissertation (Doctor of Physical Education) - Faculty of Springrield College.

32.WALSH. K. et al. Occupational causes of low-back pain. S.J.Work Environ.Health. v. 15. p.54-9. 1989. 